\title{
Mini-Invasive Extraarticular Stabilization of the Cranial Cruciate Deficient Stifle in Dogs
}

\author{
Cornel IGNA ${ }^{1 *}$, Daniel BUMB ${ }^{1}$ Larisa SCHUSZLER ${ }^{1}$, Roxana DASCALU ${ }^{1}$, Vicentiu PREDESCU ${ }^{1}$ \\ ${ }^{1}$ Banat's University of Agricultural Science and Veterinary Medicine, "King Mihai I of Romania", \\ Timisoara, Romania \\ *corresponding author: ignacornel@gmail.com
}

Bulletin UASVM Veterinary Medicine 76(2)/2019

Print ISSN 1843-5270; Electronic ISSN 1843-5378

doi:10.15835/buasvmcn-vm:2019.0012

\begin{abstract}
:
The purpose of this work was to describe three mini-invasive techniques for extraarticular stabilization of the deficient stifle based of bone anchores inserted in quasi-isometric sites.

Suture stabilization of the stifle consisted of placing a monofilament nylon leader line or polyethylene suture between femoral site adjacent to the distal poles of the fabella, and tibial site immediately cranial to the long digital extensor tendon, using two anchor types. Each stifle was tested (cranial drawer test and tibial compression test) before and after arthroscopic transection of the cranial cruciate ligament and after performing the assigned procedure. Surgical approach, order of procedural steps, drill hole entrance and exit points, and techniques for anchors placement, tensioning, and securing were described.

The results of the cranial drawer test and tibial compression test do not show statistically significant differences between the three applied techniques. All three techniques provide passive stability to the deficient stifle.
\end{abstract}

Keywords: dog, cranial cruciate ligament, extracapsular stifles stabilization, bone anchor

\section{Introduction}

The extraarticular prosthetic stabilization technique is the most popular treatments used for cranial cruciate ligament (CCL) stabilisation (Korvick et al., 1994, Tonks et al. 2011, Comerford et al., 2013), but Tibial Plateau Levelling Osteotomy (TPLO) was preferred by American and European, members of the College of Veterinary Surgeons for treating CCL rupture in dogs weighing $>15 \mathrm{~kg}$ (Von Pfeil et al., 2018).

Extraarticular stabilization techniques utilizing synthetic materials can be subcategorized to include capsular imbrication, circumfabellar prostheses, anchor, and bone tunnel techniques (Tonks et al., 2011).
The ideal localisation of femoral and tibial anchorage sites is isometric (Hyman et al., 2001, Roe et al., 2008, Hulse et al., 2010). The term "isometry" refers to a situation in which two points, one on the distal femur and one on the proximal tibia, remain at a constant distance apart throughout the stifle range of motion. True isometry is not achievable since the canine stifle does not function as a pure hinge joint and the term "quasi-isometry" was preferred by mostly of board certified surgeons (Williams and Logan, 2004, Fischer et al., 2010, Tonks et al., 2011, Roe, 2013).

Based on in vitro testing (Choate et al., 2011, Choate et al., 2013) has demonstrated 
that techniques in which the stabilizing suture is secured to the bone rather than circumfabellar provide superior load to failure, stiffness and load to yield, relative recently, two development in extraarticular prosthetic stabilization techniques were described: the use of bone anchors (Hulse et al., 2011) and the bone tunnel technique in the femur and tibia to place a braided polyester coated polyethylene suture on the lateral aspect of the stifle - "Tightrope" technique (Arthrex Vet Systems, Naples, Florida, USA) - (TR) (Cook et al., 2008, Cook, 2010, Cook et al., 2010).

In a strain analysis of femoral and tibial anchorage in dogs, three site "quasi-isometric" points were found to correspond to the femur sites on lateral condyle adjacent to the distal pole of the fabella (F2), the tibial sites immediately cranial to (T2) and caudal to (T3) the long digital extensor (LDE) tendon (Hyman et al., 2001, Roe et al., 2008, Hulse et al., 2010). In the TR procedure, two locations of isometric point combinations have been reported, in prospective clinical and biomechanical studies, for the suture anchorage, F2-T2 or F2-T3 (Cook et al., 2010, Tonks et al., 2010, Choate et al., 2013).

Cinti et al. (2015) comparing, in vitro, F2-T2 / F2-T3 in TR reconstruction by cranial drawer test (CDT), cranial tibial thrust, internal / external, range of motion and varus / valgus tests performed in different stifle conditions. Looks like the best isometric site was at the F2-T2 point, because it is relatively easy to perform, repeatable and results in good stifle stability.
Although the advantages and disadvantages of minimally invasive approaches to surgical management of CCL deficiency in dogs have been described (Hoelzler et al., 2004), TR is, after our introspective bibliographic study, the only minimally invasive procedure developed by $\mathrm{Dr}$ James Cook of the University of Missouri using the Arthrex cruciate ligament repair system to replace the function of the damaged CCL with a strong synthetic ligament directly anchored to the bones one either side of the joint.

The purpose of this work was to describe surgical approach, order of procedural steps, drill hole entrance and exit points, and techniques for anchors placement, tensioning, and securing suture for three mini-invasive techniques of the extraarticular stabilization of the deficient stifle based of bone anchores inserted in quasi-isometric site F2-T2.

\section{Materials and methods}

Sixteen stifles were used from eight dogs fresh or frozen, euthanased for reasons unrelated to the study, but without a history of locomotor deficits. Dogs, four unneutered males and four intact females, weighing between 23 to $34 \mathrm{~kg}$, belonged to the breed German Shepherd dog $(n=5)$ and mixed breed $(\mathrm{n}=3)$.

Each stifle was fluoroscopic examinated preoperative to confirm that the joints were free of pathology. In femoro-tibial specimens with intact passive joint restraints, femoral sites adjacent to the distal (F2) poles of the fabella, and tibial sites

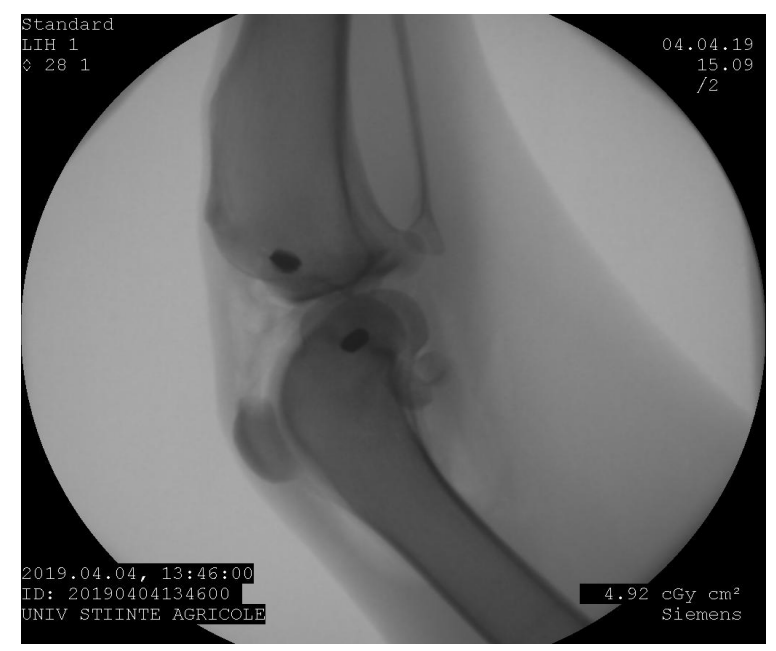

Figure 1. Femoral sites adjacent to the distal (F2) poles of the fabella, and tibial sites immediately cranial to (T2) the LDE tendon, were fluoroscopic identified. 


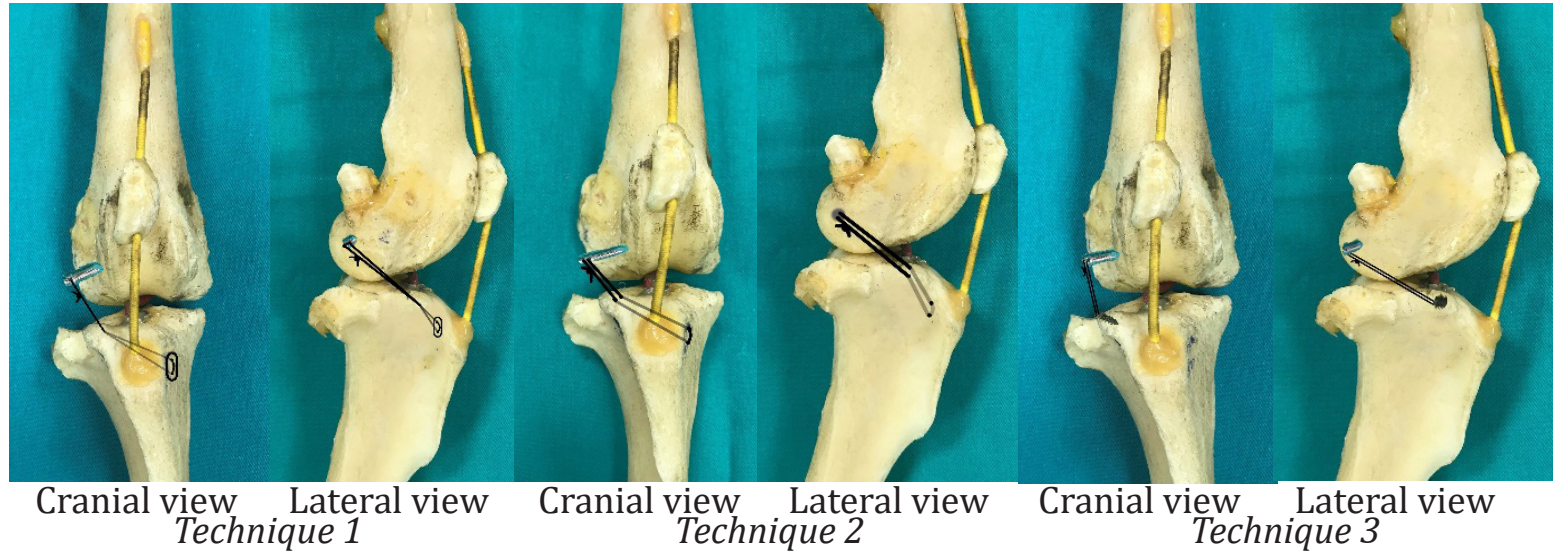

Figure 2. The three mini-invasive surgical approaches tested
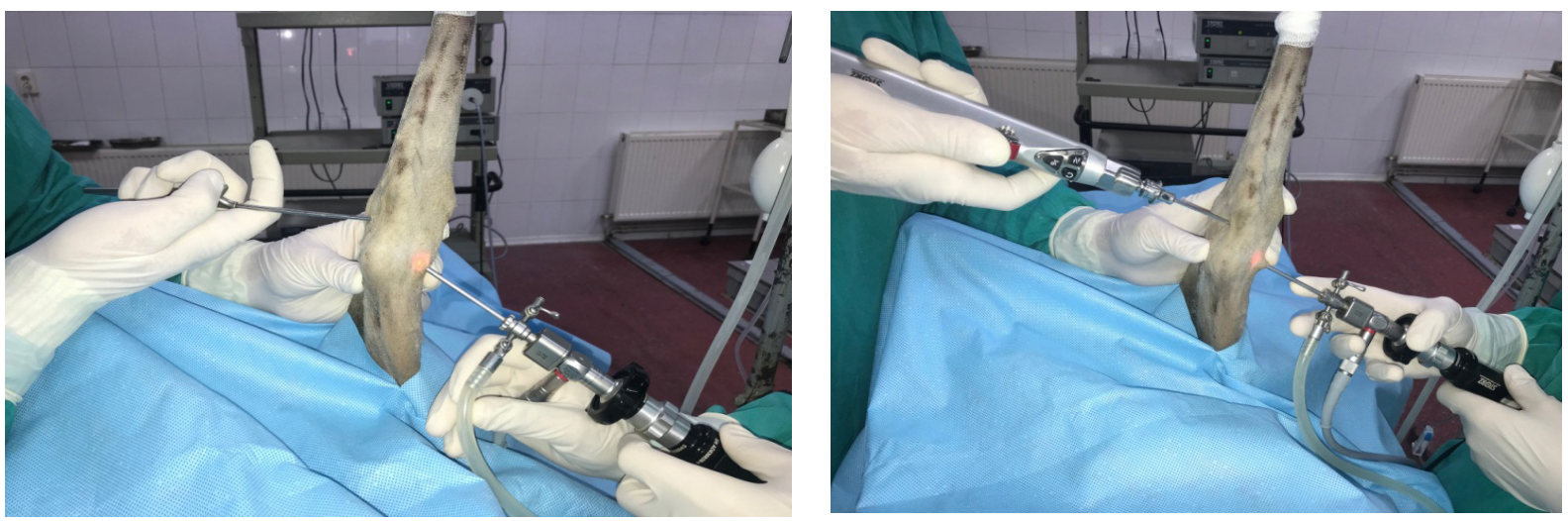

Figure 3. Arthroscopy - lateral approaches. $\mathrm{CCl}$ was cut and torn remnants were removed with a shaver

immediately cranial to (T2) the LDE tendon, were fluoroscopic identified and being marked with syringe needles (Figure 1).

One of the hind limbs was randomly assigned via drawing lots to undergo surgical extracapsular suture technique 1 or 2 or 3 and control (intact stifles - nonstabilised) $(n=4)$. Extracapsular suture stabilization of the stifle consisted of placing a suture between quasi-isometric sites F2 -T2 by three different surgical techniques (Figure 2).

Limbs were clipped and prepared for aseptic surgery using standard technique. Position the patient was done in dorsal recumbency with the limb to be operated fixed in extension (Figure 2). Each stifle was tested before by CDT and tibial compression test (TCT) - both at $120^{\circ}$ in flexion, and after arthroscopic transection of the CCL (Figure 3) and after performing the assigned surgical procedure. Each test consist in subjectively measured in millimeters by two surgeons.

Statistical analyses were performed using software calculator.net and mean and standard deviation were determined for each test. Data were assessed for significant differences using 1 -way ANOVA. For all tests, $\mathrm{P}<.05$ was considered to be statistically significant.

Surgical procedures. All surgical procedures were performed by one surgeon.

Technique 1 - F2 (Securos anchor, $4.5 \mathrm{~mm}$ ) and T2 (tibial single tunnel) with monofilament nylon leader line (MNL) - 80\#. After careful palpation, one short skin incision $(2 \mathrm{~cm})$ was made on the lateral aspect of the stifle from tibia immediately cranial to the LDE tendon (lateral tubercle of insertion of the biceps tendon / iliotibial band - tubercle of Gerdy) and another skin incision (2 $\mathrm{cm}$ ) was made in the caudal portion of the lateral femoral condyle (cranial and distal to the lateral fabella-femoral condyle junction).

After Gerdy tubercle was evidenced, one tunnel into tibia (latero-medial and easy proximodistal) was prepared by drilling using Kirschner wire drill (Figure 4). The insertion of Securos ${ }^{\circledR}$ anchor $(4.5 \mathrm{~mm})$ into the femur (F2) has been 


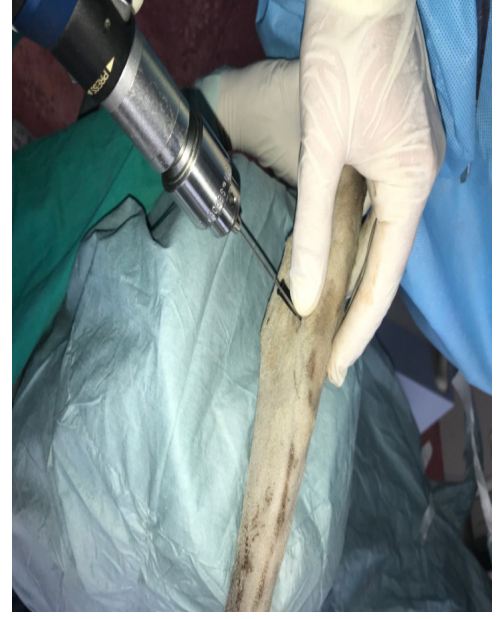

Figure 4. A tunnel in to tibia (latero-medial and easy proximo-distal) was prepared by drilling using Kirschner wire

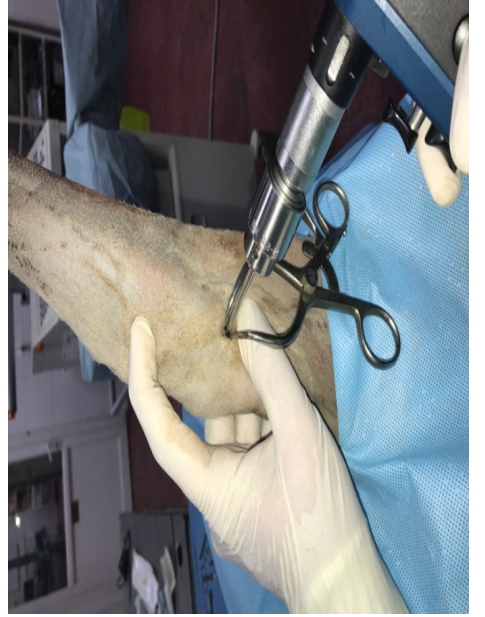

Figure 5. Insertion in to femur (F2) a Securos $\AA$ anchor $(4.5 \mathrm{~mm})$

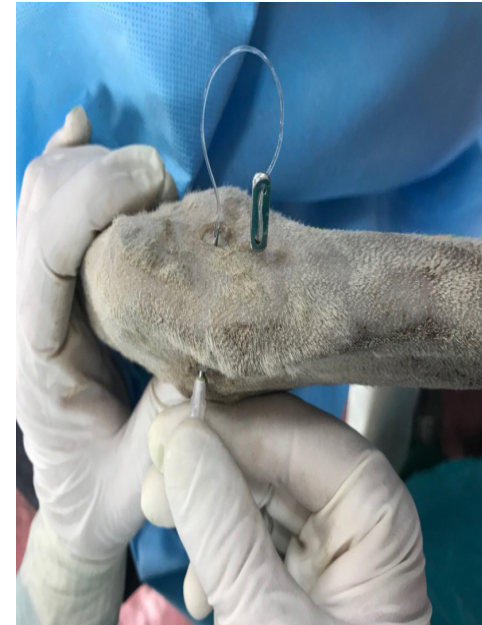

Figure 6. A toggle button was attached of the MNL thread at the proximo-medial tibial surface

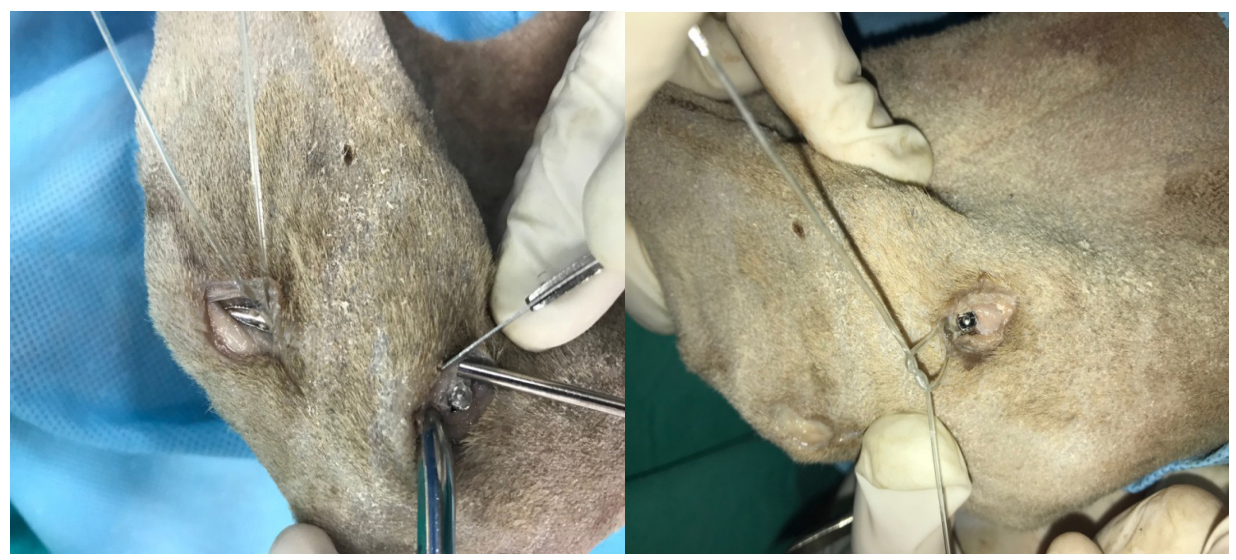

Figure 7. A - MNL passed through the soft peri-articular tissues from T2 to F2. B- Tensioning and securing suture

initiated by a drill hole made with $3.2 \mathrm{~mm}$ drill bite, followed by insertion of the bone anchor (Figure 5). A needle was advanced through the tibial tunnel from lateral to medial. Through needle one thread MNL - 80 \# was advanced on the medial aspect of the stifle and the toggle button was attached and the thread reinserted by the needle on the lateral aspect of the stifle (Figure 6).

A needle is inserted through the soft periarticular tissues from T2 to F2 leading the ends of the MNL thread. The thread is passed through the eye of the anchor (F2). Tensioning and securing suture was made with the animal placed in lateral recumbence with stifle joint in flexion $-120^{\circ}$ (figure 7). Sufficiency of stabilization was confirmed by negative CDT and TCT and proper placement of anchor by fluoroscopic image (Figure 8).

Technique 2 - F2 (Securos anchor, $4.5 \mathrm{~mm}$ ) and T2 (tibial two parallel bone tunnels) with MNL - 80\#; is similar to Technique 1 with the exception that by Gerdy tubercle two bone tunnels were drilled and through these holes MNL was inserted.

Technique 3 - F2 (Securos anchor, $3.5 \mathrm{~mm}$ ) and T2 (Livantec anchor) with 2 USP size, double strands polyethylene suture. The insertion into the femur (F2) of the Securos $\AA$ anchor $(3.5 \mathrm{~mm})$ was made similar to precedent techniques. In the Gerdy tubercle a Livantec anchor was inserted (figure 9) and the two anchor threads (polyethylene suture, 2 USP) were passed through a needle and through the soft peri-articular tissue from T2 to F2. After 

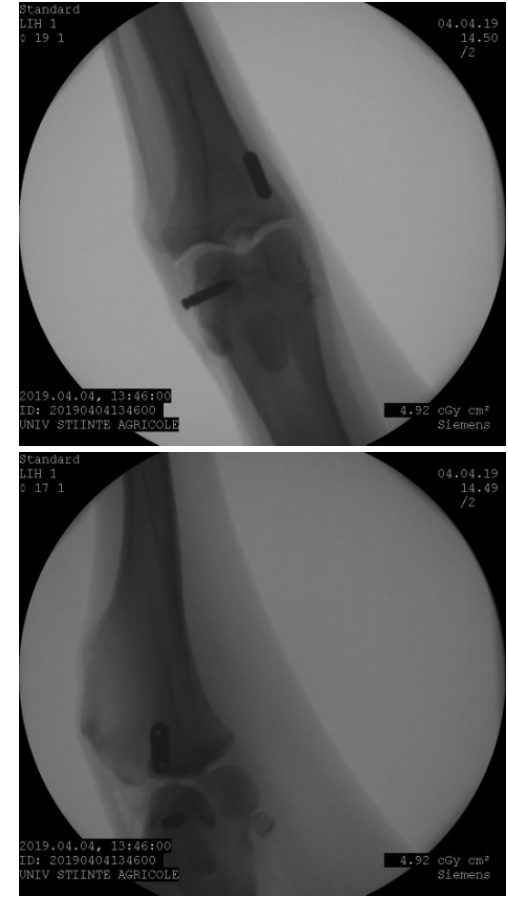

Technique 1 - F2 (Securos anchor, $4.5 \mathrm{~mm}$ ) and T2 (tibial single tunnel) with MNL - 80\#.
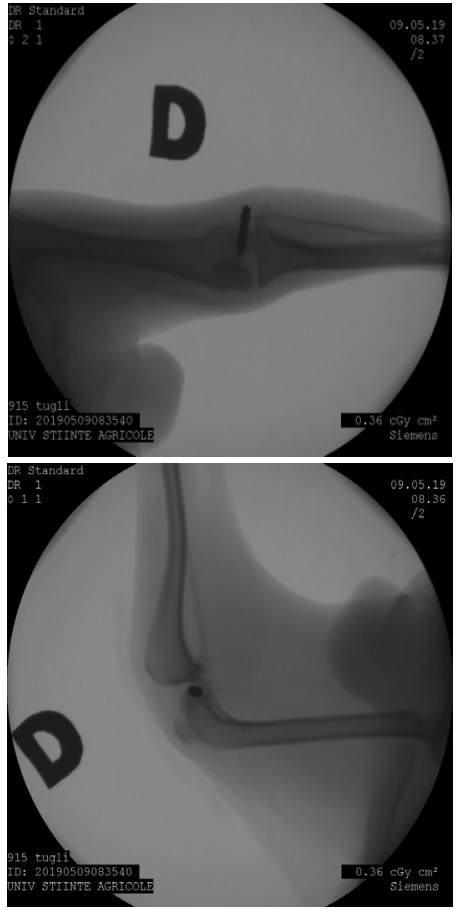

Technique 2 - F2 (Securos anchor, $4.5 \mathrm{~mm}$ ) and T2 (tibial two parallel bone tunnels) with MNL - 80\#.
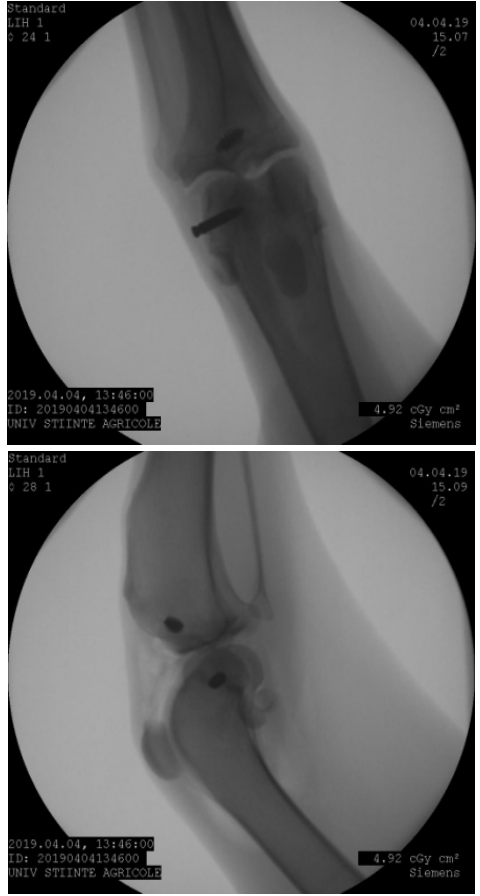

Technique 3 - F2 (Securos anchor, $3.5 \mathrm{~mm}$ ) and T2 (Livantec anchor) with 2 USP size, double strands polyethylene suture.

Figure 8. Confirmation of the proper placement of anchors by fluoroscopic image

the passage of a propylene wire through the eylet of the Securos anchor, tensioning and securing suture was made with the animal placed in lateral recumbence with a stifle joint in flexion $-120^{\circ}$. Sufficiency of stabilization was confirmed by a negative $\mathrm{CD}$ and $\mathrm{TC}$ testes and proper placement of anchors by fluoroscopic image.

\section{Results and discussions}

The purpose of this work was to describe surgical approach, order of procedural steps, drill hole entrance and exit points, and techniques for anchors placement, tensioning, and securing suture for three mini-invasive techniques of the extraarticular stabilization of the deficient stifle based of bone anchores inserted in quasi-isometric site F2-T2.

The surgical approach, for all three miniinvasive techniques of the extra-articular stabilization of the deficient stifle based of bone anchores inserted in quasi-isometric site F2$\mathrm{T} 2$, is facilitated by preoperative fluoroscopic identification and marking with syringe needles of insertion bone sites, careful palpation of the stifle and bone eminence, and fluoroscopic assisted of anchor insertion and tunnels drilling.

Quantitative outcomes of laxity tests for all of the evaluated stifle conditions (CCL intact, CCL sectioned, CCL prothezed) are shown in Figures 10 and 11.

Statistically significant differences were found between CDT and TCT compared to the intact stifle with joint after CCL resection. The diagnostic accuracy of the TCT was superior, compared with CDT. Similary results reported De Rooster et al. (1998) in a stress radiographs study beetwen radiographic TCT, where sensibility was $97 \%$ compared with $86 \%$ for CDT; the specificities of the tests were $100 \%$ and nearly $98 \%$, respectively.

However, during the $\mathrm{CD}$ and TC tests, a statistically significant $(P<.05)$ increase in craniocaudal displacement was found, compared to the intact stifle, after CCL resection. A statistically significant decrease $(\mathrm{P}<.05)$ of laxity after F2$\mathrm{T} 2$ reconstruction for all three procedures were registered, but do not show statistically significant differences between the three applied techniques. 


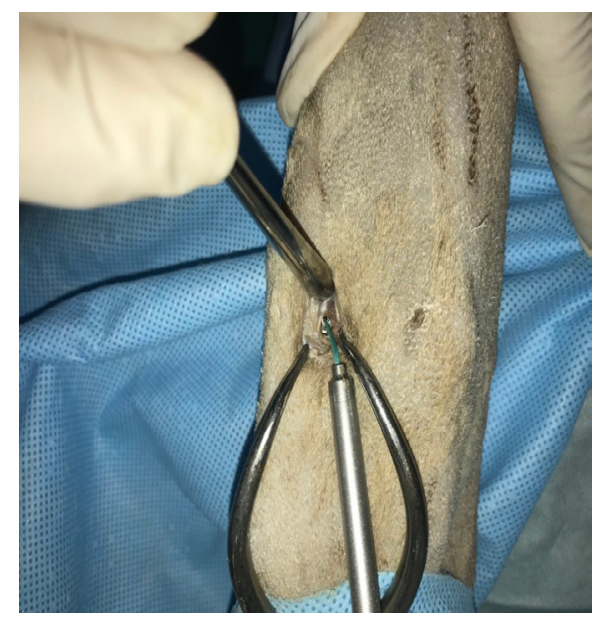

Figure 9. Insertion of Livantec anchor into Gerdy tubercle

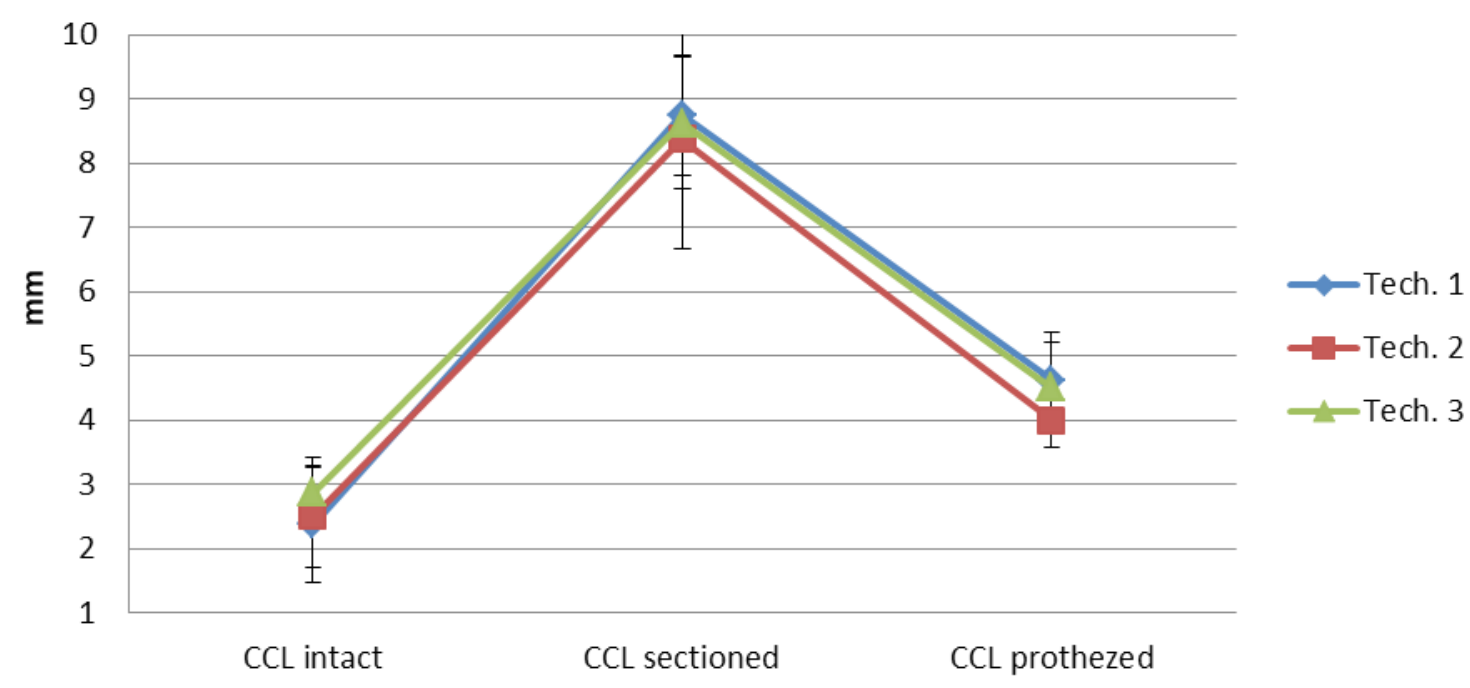

Figure 10. Comparison of the ratio of CDT (mm) variables between CCL intact, CCL deficient, after three reconstruction techniques (mean and standard deviation)

The correct application of a prosthesis is very important in extracapsular techniques, because incorrect application of the suture at a nonisometric point may result in limitation of the joint motion. In a study, Choate et al. (2011), showed unsatisfactory results (creep and elongation) after soft tissue anchorage through the femoralfabellar ligament. Hulse et al. (2010) and Fischer et al. (2010) demonstrated a significant increase in suture tension at full flexion with the suture anchored in the lateral condyle and through a tunnel drilled at Gerdy's tubercle. Excessive tension in extracapsular procedures could lead to external rotation and excessive compression of the lateral intra-articular compartment (Chailleux et al., 2007, Hulse et al., 2010, Tonks et al., 2010).
Moreover, this excessive tension could result in possible damage of the meniscus and less functionality of the joint. This is in accordance with the study of Tonks et al. (2010).

However, in a recent study betwen F2-T2 and F2-T3 anchorage of TR method, Cinti et al. (2015) indicates the best isometric sites for extracapsular stifle stabilization are F2-T2 points.

The tibial site recommended by Hulse et al. (2011) which gives the least increase in suture tension is located at the bony protuberance caudal to the sulcus of the LDE. Cinti et al. (2015) shows that the point indicated by Hulse et al. (2011), T3 - presents an anatomical conformation that makes the tibial tunnel execution more complicated in comparison to the easier approach of $\mathrm{T} 2$. 


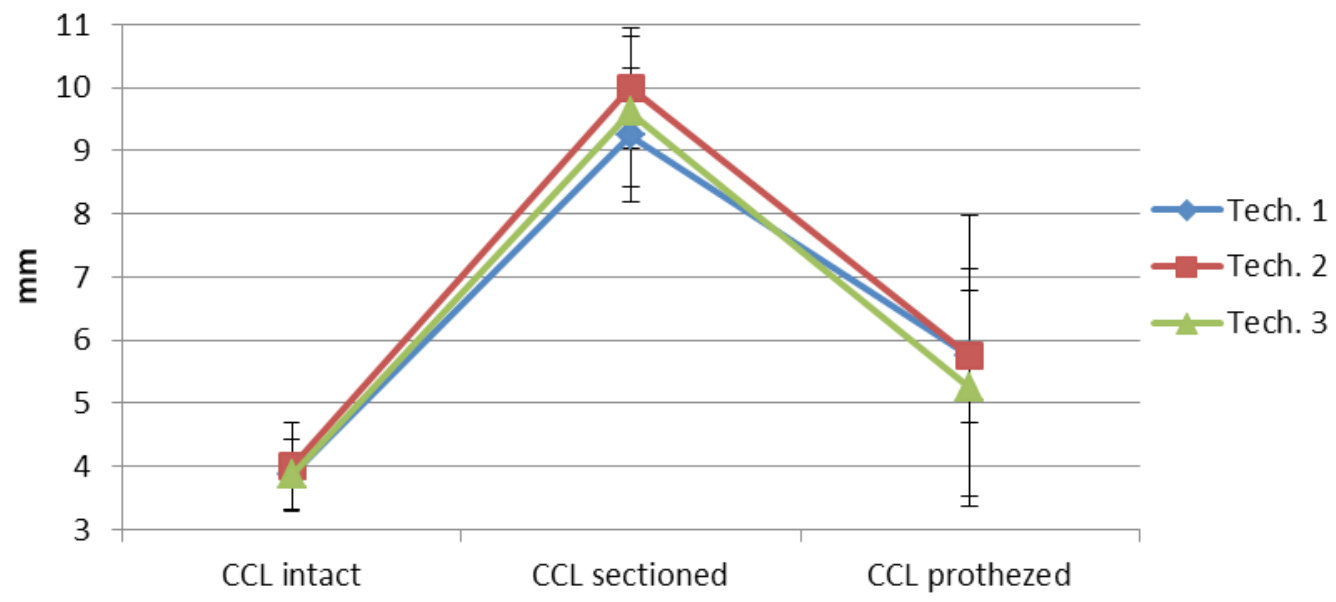

Figure 11. Comparison of the ratio of TCT (mm) variables between CCL intact, CCL deficient, after three reconstruction techniques (mean and standard deviation)

The results of this study concerning the reduction of cranio-caudal displacement are in agreement with previous studies by Cook (2010), Cook et al. (2010), Cinti et al. (2015), and Christopher et al. (2013), after TR stabilisation between quasi-isometric points F2-T2.

The correct application of the isometric points and the correct tension of the implant therefore represent the correct approach for a successful extracapsular CCL reconstruction.

Our study has few limitations. The study is based only on preoperative and on single immediate post-reconstruction assessment by clinical palpation techniques, through which the joint stability was assessed. Other limitations are a lack of evaluation of the limb under physiological loads, ex vivo model is limited by the absence of the muscular forces present in vivo. Muscles are important contributors of joint reaction force that play a significant role in stifle joint stability (Cinti et al., 2015).

\section{Conclusion}

The all three mini-invasive techniques of the extraarticular stabilization of the deficient stifle based of bone anchores inserted in quasi-isometric site F2-T2 are easy to be performed, repeatable and in vitro results indicates a good stifle stability.

Future studies involving in vivo models as well as kinematic analysis are necessary to validate the mini-invazive methods proposed.

Acknowledgments. This research did not receive any specific grant from funding agencies in the public, commercial, or not-for-profit sectors.

\section{References}

1. Chailleux N, Lussier B, De Guise J, Chevalier Y, Hagemeister $N$ (2007). In vitro 3-dimensional kinematic evaluation of 2 corrective operations for cranial cruciate ligamentdeficient stifle. Canadian Journal of Veterinary Research, 71: $175-180$.

2. Choate CJ, Lewis DD, Conrad BP, Horodyski MB, Pozzi A (2013). Assessment of the craniocaudal stability of four extracapsular stabilization techniques during two cyclic loading protocols: a cadaver study. Veterinary Surgery, 42(7): 853-859.

3. Choate CJ, Pozzi A, Lewis DD, Conrad BP, Hudson CC (2011). Mechanical testing of Lateral Circumfabellar Suture, Tightrope CCL, and SwiveLock Bone Anchor for Extracapsular Stabilization of the Cranial Cruciate Ligament-deficient Stifle in Dogs. Proceedings of the 38th Annual Veterinary Orthopedic Society Meeting, Snowmass, 5-12 March, pp. 36.

4. Christopher SA, Beetem J, Cook JL (2013). Comparison long-term outcomes associated with three surgical techniques for treatment of cranial cruciate ligament disease in dogs. Veterinary Surgery, 42: 329-334.

5. Cinti F, Signorelli C, Lopomo N, Baracchi M, Del Magno S, Foglia A, Zaffagnini S, Pisoni L (2015). Two different approaches for novel extracapsular cranial cruciate ligament reconstruction: an in vitro kinematics study. Journal of Small Animal Practice, 56(6): 398-406.

6. Comerford E, Forster K, Gorton K, Madox (2013). Management of cranial cruciate ligament rupture in small dogs: a questionnaire study. Veterinary and Comparative Orthopaedics and Traumatology, 26: 493-497.

7. Cook JL, Luther JK, Beetem J, Cook CR (2008). Tightrope CCL for treatment of cranial cruciate deficiency in dogs: Tehnique and prospective comparison to TPLO at 6 months postoperative. (abstract) Proc Vet Orthop Soc. 8-15 March, Big Sky, Montana, pp. 15.

8. Cook JL (2010). Multicenter outcomes study for evaluation of Tightrope CCL for treatment of cranial cruciate 
deficiency in dogs: The first 1000 cases. Veterinary and Comparative Orthopaedics and Traumatology, 3: A2.

9. Cook JL, Luther JK, Beetem J, Karnes J, Cook CR (2010). Clinical comparison of a novel extracapsular stabilization procedure and tibial plateau levelling osteotomy for treatment of cranial cruciate ligament deficiency in dogs. Veterinary Surgery, 39(3): 315-323.

10. De Rooster H, Van Ryssen B, van Bree H (1998). Diagnosis of cranial cruciate ligament injury in dogs by tibial compression radiography. Veterinary record, 142(14): 366-368.

11. Fischer C, Cherres M, Grevel V, Oechtering G, Böttcher $P$ (2010). Effects of attachment sites and joint angle at the time of lateral suture fixation on tension in the suture for stabilization of the cranial cruciate ligament deficient stifle in dogs. Veterinary Surgery, 39(3): 334-342.

12. Hoelzler MG, Millis DL, Francis DA, Weigel JP (2004). Results of arthroscopic versus open arthrotomy for surgical management of cranial cruciate ligament deficiency in dogs. Veterinary Surgery, 33(2): 146-153.

13. Hulse D, Hyman W, Beale B, Saunders B, Hosgood G (2010). Determination of isometric points for placement of a lateral suture in treatment of the cranial cruciate ligament deficient stifle. Veterinary and Comparative Orthopaedics and Traumatology, 23(03): 163-167.

14. Hulse D, Saunders B, Beale B, Kowaleski M (2011). Extraarticular stabilisation of the cranial cruciate deficient stifle with anchor systems. Tierärztliche Praxis. Ausgabe K, Kleintiere/ Heimtiere, 39: 363-367.

15. Hyman W, Hulse DS, Saunders B, Diezysic J, Beale B, Whitney W (2001). Strain analysis of femoral and tibial anchorage sites for extra-articular reconstruction of the cranial cruciate deficient stifle joint. Proceedings of the 28th Annual Conference of the Veterinary Orthopaedic Society. Lake Louise, Canada, 24 February -2 March, 32-40, Veterinary and Comparative Orthopaedics and Traumatology,14: A6.

16. Korvick DL, Johnson AL, Schaeffer DJ (1994). Surgeons' preferences in treating cranial cruciate ligament ruptures in dogs. Journal of the American Veterinary Medical Association, 205: 1318-1324.

17. Roe SC (2013). The challenge of isometry for extracapsular devices [VII. Abstract]. Veterinary and Comparative Orthopedics and Traumatology, 26: 2.

18. Roe SC, Kue J, Gemma J (2008). Isometry of potential suture attachment sites for the cranial cruciate ligament deficient canine stifle. Veterinary and Comparative Orthopaedics and Traumatology, 21(03): 215-220.

19. Tonks CA, Lewis DD, Pozzi A (2011). A review of extraarticular prosthetic stabilization of the cruciate ligamentdeficient stifle. Veterinary and Comparative Orthopaedics and Traumatology, 24: 166-177.

20. Tonks CA, Pozzi A, Ling HY, Lewis DD (2010). The effects of extra-articular suture tension on contact mechanics of the lateral compartment of cadaveric stifles treated with the TightRope CCL $®$ or lateral suture technique. Veterinary Surgery, 39(3): 343-349.

21. Von Pfeil DJ, Kowaleski MP, Glassman M, Dejardin LM (2018). Results of a survey of Veterinary Orthopedic Society members on the preferred method for treating cranial cruciate ligament rupture in dogs weighing more than 15 kilograms (33 pounds). Journal of the American Veterinary Medical Association, 253(5): 586-597.

22. Williams A, Logan M (2004). Understanding tibio-femoral motion. Knee, 11: 81-88. 